\title{
Prevalence and factors associated with depression among pregnant mothers in the West Shoa zone, Ethiopia: a community-based cross-sectional study
}

\author{
Takele Tiki ${ }^{1}$, Kefyalew Taye ${ }^{2}$ and Bereket Duko, ${ }^{3,4^{*}}$ (D)
}

\begin{abstract}
Background: Depression during pregnancy, the most prevalent mental health problem, can alter fetal development and has important consequences on the offspring's physical and mental health. Evidence suggests increasing rates of prevalence of depression in low-income settings such as Ethiopia. However, there are a few studies on the topic with inconsistent results. Therefore, the aim of this study was to investigate the prevalence of antenatal depression and its correlates among pregnant women in Ethiopia.
\end{abstract}

Methods: A community-based cross-sectional study was conducted in the West Shoa zone, Oromia regional state, Ethiopia, from February 20, 2018, to March 20, 2018. Pregnant women were recruited by using cluster sampling techniques. Data on socio-demographic, obstetric, and psychosocial characteristics were collected by intervieweradministered questionnaire. Patient Health Questionnaire (PHQ-9) was used to assess depression during pregnancy. Bivariable and multivariable logistic regression analyses were fitted to identify correlates of depression. The level of statistical significance was declared at $p$ value $<0.05$.

Results: The mean age $( \pm S D)$ of the pregnant women was $28.41 \pm 5.9$ years. The prevalence of depression during pregnancy was $32.3 \%$. When we adjusted for possible confounding variables in the final model; those pregnant mothers with an average monthly income of less than 500 (18 USD) Ethiopian birr [AOR $=3.19,95 \% \mathrm{Cl}(1.47,6.96)]$, unplanned pregnancy $[A O R=1.52,95 \% \mathrm{Cl}(1.04,2.21)]$ and having history of abortion $[A O R=5.13,95 \% \mathrm{Cl}(2.42$, 10.85)] have higher odds of depression when compared to their counterparts.

Conclusion: The prevalence of depression during pregnancy was high. Strengthening the counseling service as well as increasing access and availability of modern contraceptive methods may reduce the rates of unplanned pregnancy in Ethiopia and this, in turn, plays a significant role in alleviating a resultant depression. Further, the integration of mental health services with existing maternal health care as well as strengthening the referral system among public health centers was warranted to minimize antenatal depression in the West Shoa zone health facilities.

Keywords: Depression, Pregnancy, Community, Ethiopia

*Correspondence: berkole.dad@gmail.com

${ }^{3}$ Faculty of Health Sciences, College of Medicine and Health Sciences, Hawassa University, Hawassa, Ethiopia

Full list of author information is available at the end of the article

\section{Background}

Depression, also known as major depressive disorder, is a mental health problem characterized by at least 2 weeks of depressed mood that is present across most situations and accompanied by low self-esteem, loss of interest in

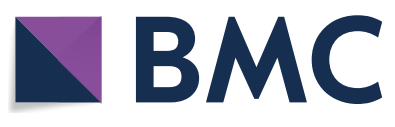

(c) The Author(s) 2020. This article is licensed under a Creative Commons Attribution 4.0 International License, which permits use, sharing, adaptation, distribution and reproduction in any medium or format, as long as you give appropriate credit to the original author(s) and the source, provide a link to the Creative Commons licence, and indicate if changes were made. The images or other third party material in this article are included in the article's Creative Commons licence, unless indicated otherwise in a credit line to the material. If material is not included in the article's Creative Commons licence and your intended use is not permitted by statutory regulation or exceeds the permitted use, you will need to obtain permission directly from the copyright holder. To view a copy of this licence, visit http://creativeco mmons.org/licenses/by/4.0/. The Creative Commons Public Domain Dedication waiver (http://creativecommons.org/publicdomain/ zero/1.0/) applies to the data made available in this article, unless otherwise stated in a credit line to the data. 
daily activities, low energy, guilty feeling and death wish [1]. According to the World Mental Health Survey, on average 1 in 20 individuals has at least one episode of depression in their lifetime [2]. The World Health Organization (WHO) predicted depression to become the second leading causes of global disability burden by the year 2020 [2]. Further, depression led to a worldwide total of over 50 million Years Lived with Disability (YLD) in 2015 and over $80 \%$ of this disease burden occurred in low- and middle-income countries [3, 4].

In developed countries, the prevalence of prenatal depression is estimated to be $720 \%$ [5]; whereas, in developing countries $25 \%$ [6]. Depression commonly appears during pregnancy in resource-limited settings [6] and approximately one in three women has a significant mental health problem [5]. However, it is left undiagnosed in low- and middle-income countries, making a substantial contribution to maternal and infant morbidity $[7,8]$. The type of tools used to screen depressive symptoms, the study design and setting, the trimester of pregnancy, psychosocial, socio-economic and cultural disparities are the commonly reported reasons for the variations of antenatal depression in developed and developing countries [6-10].

Antenatal depression may be related to numerous risk factors and its occurrence suggestively increases during the mid- and late-trimesters [11]. Findings from different studies showed that the associations between antenatal depression and previous history of psychiatric illness, pregnancy-related complications like stillbirth and history of abortion [12]. Further, it is also associated with perinatal outcomes, growth and development of the previous child [13,14], past history of depression, unplanned pregnancy [15], single marital status, having thoughts of perceived stress [16], lower educational level, suffering and having history of abuse [17].

Evidence from different studies suggests the intergenerational transmission and progression of depression to adulthood [18-20]. A study from the UK assessed the intergenerational transmission of depression from mothers to offspring [20]. In this study, exposure to prenatal depression by age of 12 years predicated the progression of depression in adolescence. Adjusting such potential mediators in the statistical models may increase the robustness of the estimates. Antenatal depression was also associated with the socio-economic status of women. For example, a population-based cohort study conducted in the Netherlands that included a total of 5398 pregnant mothers reported a statistically significant association between antenatal depression and income [21].

In Ethiopia, there were a few studies with inconsistent results. For example, cross-sectional studies conducted to assess the prevalence of antenatal depression in the northern and central Ethiopia reported 11.8\% [22] and $31.1 \%$ [23], respectively. Besides, most of the studies were conducted in the clinical setting which plays a significant role in the variation of the prevalence of depression in the antenatal period. Therefore, this study aimed to assess the prevalence of depression and identify associated factors among pregnant mothers in the community setting of Ethiopia.

\section{Methods}

\section{Study design and setting}

A community-based cross-sectional study was employed. The study was conducted in the West Shoa zone, Oromia regional state, Ethiopia. The west Shoa zone has a total of 23 woredas (districts) including Ambo town. The projected population of the West Shoa zone is about 2.6 million (1.3 million men and 1.3 women) population. During the study period, there were 26,7399 pregnant women with 17, 9160 of which are in the 2nd and 3rd trimester of pregnancy. The assessment was conducted from February 20, 2018, to March 20, 2018.

\section{Sample size estimation and recruitment of participants} Single population proportion formula was used to calculate the sample size using the magnitude of depression in pregnant mothers in Ethiopia, 31.1\% [23], with a 95\% confidence interval, $5 \%$ of margin error and with the calculated design effect of 2.5. A cluster sampling technique was employed to select three woredas, such as Jeldu, Ambo, and Bako out of 23 woredas. Health extension workers of each woreda listed pregnant mothers using the non-identifying registration code. We have used this registration as a sampling frame to recruit the study participants. A total of 874 pregnant mothers who were in the second or third trimester of pregnancy, lived and currently living in the study area for at least the preceding 1 year were recruited for the study. Those with hearing or cognitive impairment to the extent of impairing capacity to communicate adequately and unable to give informed consent to take part in the study were excluded from the study.

\section{Data collection instrument and data collectors}

Data were collected by trained data collectors. The presence of antenatal depression was assessed by the Patient Health Questionnaire item nine (PHQ-9). This scale has been validated to use among pregnant women in the community setting with the minimum cut-off point of 8 or more suggest depression [24]. This is a highly reliable scale with a sensitivity of $80.8 \%$ and a specificity of $79.5 \%$ to assess depression. Its reliability coefficient, Cronbach's alpha, and 1-week test-retest were 0.84 and 0.98 , respectively. Perceived stress scale was also used 
in the study. It is a 10-item Likert scale; each item has 5 possible responses measuring the frequency of perceived stress over the last month $[25,26]$. These 10 items are to assess stress due to events, feeling out of control, and feeling rushed or short on time. It has been used in different studies conducted in Ethiopia. It was highly reliable in our study with Cronbach's alpha of 0.92 . We have used the Ethiopian Demographic and Health Survey (EDHS) of 2016 formats to assess other pregnancy-related information (like previous stillbirth, spontaneous abortion, neonatal and infant mortality, and comorbid medical conditions, actual antenatal visits and birth preparedness) [27].

\section{Operational definitions Antenatal depression}

A score of 8 or more in the Patient Health Questionnaire item nine (PHQ-9) was considered depression in this study [24].

\section{Perceived stress}

The scores above mean in perceived stress scale were considered perceived stress in this study $[25,26]$.

\section{Abortion}

It is the ending of a pregnancy by removal or expulsion of an embryo or fetus before it can survive outside the uterus. In this study, it includes spontaneous abortion and induced abortion.

\section{Data analysis}

The Statistical Package for Social Science (SPSS) version 21.0 was used for data analysis. Pregnant mothers' socio-demographic, economic and obstetric characteristics were described using the statistics of frequency and percentage distributions. Further, bivariate logistic regression analysis was conducted to identify correlates of antenatal depression. Variables with a p-value $<0.25$ during bivariate analysis were entered into a multivariate logistic regression analysis to identify potential confounders. Then, adjusted OR was calculated using multivariate logistic regression analysis and the level of significance of association was determined. Significance level was declared at $<0.05$.

\section{Results}

\section{Socio-demographic characteristics of respondents}

A total of 862 pregnant mothers were included in the study yielding a response rate of $98.6 \%$. The mean age $( \pm \mathrm{SD})$ of the pregnant mothers was $28.41 \pm 5.9$ years. Out of 862 pregnant mothers, 748 (86.8\%) were from the Oromo ethnic group, $342(29.7 \%)$ had no formal education, 746 (86.5\%) were housewives and 668 (77.5\%) were from rural residence area (Table 1).

\section{Obstetric characteristics}

Regarding the obstetric characteristics, 612 (71\%) of the pregnant mothers had planned their current pregnancy, 258 (29.9\%) of the pregnant mothers had four or more gravidity and 108 (12.5\%) had a history of chronic illness. Forty (4.6\%) of the pregnant mothers had a history of depression. Further, 50 (5.8\%) of the pregnant mothers experienced spontaneous abortion in their previous pregnancy (Table 2).

\section{Prevalence and factors associated with antenatal depression}

The prevalence of antenatal depression was $32.3 \%$. The following variables were not significantly associated with antenatal depression in the bivariate analysis: ethnic group, religion, marital status, educational status,

Table 1 Socio-demographic characteristics of the included women $(n=862)$ in West Shoa zone, Ethiopia, 2018

\begin{tabular}{|c|c|c|}
\hline Variables & Frequency & Percentage \\
\hline \multicolumn{3}{|l|}{ Age of respondents } \\
\hline $15-24$ & 215 & 24.9 \\
\hline $25-34$ & 450 & 52.2 \\
\hline$\geq 35$ & 197 & 22.9 \\
\hline \multicolumn{3}{|l|}{ Ethnicity of respondents } \\
\hline Oromo & 748 & 86.8 \\
\hline Amhara & 62 & 7.2 \\
\hline Others & 52 & 6.0 \\
\hline \multicolumn{3}{|l|}{ Religion of respondents } \\
\hline Orthodox & 458 & 53.1 \\
\hline Protestant & 365 & 42.3 \\
\hline Others & 39 & 4.5 \\
\hline \multicolumn{3}{|l|}{ Educational status } \\
\hline No formal education & 342 & 39.7 \\
\hline Primary education & 371 & 43.0 \\
\hline Secondary education & 103 & 11.9 \\
\hline Diploma and above & 46 & 5.3 \\
\hline \multicolumn{3}{|l|}{ Occupational status } \\
\hline House wives & 99 & 11.5 \\
\hline Merchant & 697 & 80.9 \\
\hline Others & 66 & 7.7 \\
\hline \multicolumn{3}{|l|}{ Monthly family income } \\
\hline$<500$ ETB & 340 & 39.4 \\
\hline 500-1500 ETB & 381 & 44.2 \\
\hline$\geq 1500$ ETB & 141 & 16.4 \\
\hline \multicolumn{3}{|l|}{ Residence } \\
\hline Urban & 194 & 22.5 \\
\hline Rural & 668 & 77.5 \\
\hline
\end{tabular}


Table 2 Pregnancy-related factors of women $(n=862)$ in West Shoa zone, Ethiopia, 2018

\begin{tabular}{|c|c|c|}
\hline Variables & Frequency & Percentage \\
\hline \multicolumn{3}{|l|}{ Number of gravidity } \\
\hline$<2$ & 318 & 36.9 \\
\hline 23 & 286 & 33.2 \\
\hline$>4$ & 258 & 29.9 \\
\hline \multicolumn{3}{|l|}{ Parity } \\
\hline Multipara & 559 & 64.8 \\
\hline Primipara & 303 & 35.2 \\
\hline \multicolumn{3}{|l|}{ Pregnancy intention } \\
\hline Intended & 612 & 71.0 \\
\hline Unintended & 250 & 29.0 \\
\hline \multicolumn{3}{|c|}{ Place of birth preceding most recent } \\
\hline Home & 526 & 61.0 \\
\hline Health institution & 336 & 39.0 \\
\hline \multicolumn{3}{|l|}{ Mode of delivery } \\
\hline Spontaneous vaginal delivery & 725 & 84.1 \\
\hline Instrumental delivery & 91 & 10.6 \\
\hline Cesarean section & 46 & 5.3 \\
\hline \multicolumn{3}{|l|}{ The most recent birth attended by } \\
\hline Relative & 376 & 43.6 \\
\hline TBA & 150 & 17.4 \\
\hline Health workers & 336 & 39.0 \\
\hline \multicolumn{3}{|c|}{ History of complication during delivery } \\
\hline Yes & 222 & 25.8 \\
\hline No & 640 & 74.2 \\
\hline \multicolumn{3}{|l|}{ History of abortion } \\
\hline Yes & 50 & 5.8 \\
\hline No & 812 & 94.2 \\
\hline \multicolumn{3}{|l|}{ History of still birth } \\
\hline Yes & 99 & 11.5 \\
\hline No & 763 & 88.5 \\
\hline \multicolumn{3}{|c|}{ ANC visit during previously pregnancy } \\
\hline Yes & 448 & 52.0 \\
\hline No & 414 & 48.0 \\
\hline \multicolumn{3}{|l|}{ ANC visit during last pregnancy } \\
\hline Yes & 615 & 71.3 \\
\hline No & 247 & 28.7 \\
\hline \multicolumn{3}{|l|}{ History of chronic illness } \\
\hline Yes & 108 & 12.5 \\
\hline No & 754 & 87.5 \\
\hline \multicolumn{3}{|c|}{ Symptoms of pregnancy complication } \\
\hline Yes & 202 & 23.4 \\
\hline No & 660 & 76.6 \\
\hline \multicolumn{3}{|l|}{ History of depression } \\
\hline Yes & 40 & $4.6 \%$ \\
\hline
\end{tabular}

occupational status, number of gravidity, number of parity, previous place of delivery, mode of delivery, previous complication during birth, history of stillbirth in lifetime, history of chronic illness and age of respondents. However, an average monthly income of the family, planned pregnancy, perceived stress and previous history of abortion were statistically associated with depression in the bivariate analysis. In the multivariable analysis, the prevalence of antenatal depression was significantly higher among women who did not have plan for the current pregnancy. Women who did not have a plan for their current pregnancy were 1.52 times more likely to have antenatal depression than those who planned for their current pregnancy [AOR $=1.52$; 95\% CI 1.042.21]. The odds of having antenatal depression increases by fivefold in pregnant women who had a previous history of abortion in their lifetime when compared to pregnant women who had no history of abortion in their lifetime $[\mathrm{AOR}=5.13 ; 95 \% \mathrm{CI} 2.4210 .85]$. Those pregnant women with a low level of income (monthly income of less than 500 ETB) were 3.19 times more likely to develop antenatal depression when compared to those who earned a monthly income of more than 1500 ETB $[\mathrm{AOR}=3.19$; 95\% CI 1.476.96] Table 3.

\section{Discussion}

The objective of the present research was to assess the prevalence of depression and to identify associated factors among a sample of pregnant mothers in Ethiopia. In this study, the prevalence of depression during pregnancy was $32.3 \%$ which is suggestive of a greater probability of antenatal depression (using a PHQ9 cut-off score $\geq 8$ ) among pregnant mothers. Some of the previous studies from Tanzania [28] and Ethiopia [29] reported an almost similar prevalence of $33.8 \%$ and $31.5 \%$, respectively. Additional studies from Pakistan [30-32], South Africa [16, 33, 34] and Kenya [35] revealed much higher rates of prevalence of depression during pregnancy, whereas Duko et al. and Biratu and Haile [36, 37] from Ethiopia, Ogbo et al. from Australia [38] and Thompson and Ajayi from Nigeria [39] observed much lower rates of prevalence of antenatal depression. These variations in the prevalence of depression during pregnancy could be attributed to the difference in the study setting, sociodemographic characteristics and the tools used to screen depression among pregnant mothers.

Pregnant women with a low level of income were 3.19 times more likely to develop depression during pregnancy when compared to their counterparts. This is also supported by findings from other studies [23, 39, 40] reporting that the risk of depression during pregnancy will be greater in pregnant mothers with a low level of income. For example, a population-based cohort study conducted in the Netherlands that included a total of 5398 pregnant mothers to investigate the association between maternal socio-economic position and depression reported a 
Table 3 Factors associated with depression among pregnant mothers in West Shoa, Ethiopia, 2018 $(\mathrm{n}=\mathbf{8 6 2})$

\begin{tabular}{llll}
\hline Variables & Depression & COR $(95 \% \mathrm{Cl})$ & AOR $(95 \% \mathrm{Cl})$ \\
\cline { 2 - 4 } & Yes No &
\end{tabular}

\begin{tabular}{|c|c|c|c|c|}
\hline \multicolumn{5}{|c|}{ Age of respondents } \\
\hline $15-24$ years & 62 & 153 & 1.00 & 1.00 \\
\hline $25-34$ years & 136 & 314 & $1.07(0.75,1.53)$ & $0.63(0.41,1.97)$ \\
\hline$\geq 35$ years & 80 & 117 & $1.69(1.12,2.54)$ & $0.88(0.54,1.43)$ \\
\hline \multicolumn{5}{|c|}{ Monthly family income } \\
\hline$<500$ & 151 & 189 & $4.09(2.49,6.73)$ & $3.19(1.47,6.96)^{*}$ \\
\hline $500-1500$ & 104 & 277 & $1.93(1.17,3.18)$ & $1.80(0.83,3.92)$ \\
\hline$\geq 1500$ & 23 & 118 & 1.00 & 1.00 \\
\hline \multicolumn{5}{|l|}{ Residence } \\
\hline Urban & 40 & 154 & 1.00 & 1.00 \\
\hline Rural & 238 & 430 & $2.13(1.45,3.12)$ & $1.56(0.95,2.49)$ \\
\hline \multicolumn{5}{|c|}{ Pregnancy plan } \\
\hline Planned & 164 & 436 & 1.00 & 1.00 \\
\hline Unplanned & 114 & 148 & $2.05(1.51,2.77)$ & $1.52(1.04,2.21)^{*}$ \\
\hline \multicolumn{5}{|c|}{ Symptoms of pregnancy complication } \\
\hline Yes & 84 & 113 & $1.81(1.30,2.51)$ & $1.33(0.89,1.99)$ \\
\hline No & 194 & 471 & 1.00 & 1.00 \\
\hline \multicolumn{5}{|c|}{ History of abortion in life time } \\
\hline Yes & 33 & 17 & $4.49(2.46,8.22)$ & $5.13(2.42,10.85)^{*}$ \\
\hline No & 245 & 567 & 1.00 & 1.00 \\
\hline \multicolumn{5}{|c|}{ Perceived stress } \\
\hline Yes & 86 & 132 & $1.53(1.11,2.11)$ & $1.29(0.87,1.88)$ \\
\hline No & 192 & 452 & 1.00 & 1.00 \\
\hline \multicolumn{5}{|c|}{ History of depression } \\
\hline Yes & 22 & 18 & $2.70(0.98,4.33)$ & $1.33(0.75,2.75)$ \\
\hline No & 256 & 566 & 1.00 & 1.00 \\
\hline
\end{tabular}

Variables that were used for the adjustment: history of abortion, perceived stress, pregnancy intention, age of the respondents

*Significant at $p$-value $<0.05,1.00$-reference group

statistically significant association between depression during pregnancy and income [21]. Further, a study that investigated the influence of early childhood and early adolescent cumulative socio-economic adversity on the occurrence of depression using a sample of 12,424 has shown a similar association [41].

Unplanned pregnancy increased the odds of depression during pregnancy. The probability of having depression during pregnancy is greater given an unplanned pregnancy $[30,35]$. Epidemiological evidence suggests that planned pregnancies are linked with reduced adverse pregnancy and birth outcomes. For example, a prospective cohort study conducted to investigate pregnancy intention of 4244 pregnant women in Malawi reported that having planned pregnancies were linked with minimal risk of depression in women [42]. This is also supported by a community-based study that showed a similar result [43]. An unplanned pregnancy may result from non-use of contraceptive services, contraceptive failure and maybe from rape [44]. These women will develop depression as a result of stress which is linked with the transition into unintended motherhood and minimal social support received from her partner. However, some of the previous studies did not report such associations [45, 46]. Moreover, strengthening the counseling service and increasing access and availability of modern contraceptive methods may reduce the rates of unplanned pregnancy in Ethiopia and play a significant role in alleviating a resultant depression.

The previous history of abortion was found to have a more significant influence on maternal depression during pregnancy when compared with those who did not have a previous history of abortion. Previous studies also reported similar associations [13, 23, 44]. For example, a study that investigated the association between abortion and risk of subsequent depression in pregnant women showed that women with a history of abortion were more likely to have depression ( $\mathrm{AOR}=3.5$; $95 \%$ CI 2.06.1) [47]. In a comprehensive literature review of 2018, abortion has been associated with higher rates of mental health problems when compared to women without a history of abortion $[48,49]$. Further, evidence from a prospective cohort study also showed a 30\% relative increase in the rate of depression among women who reported a history of abortion when compared to those who did not [50]. Pregnancy after an abortion may be psychologically and emotionally distressing. As a result, women who experienced abortion may worry about not being able to conceive or losing the current pregnancy, and this may result in depression during the current pregnancy.

\section{Conclusion}

The prevalence of depression during pregnancy in the West Shoa zone, Oromia regional state, Ethiopia, is high at $32.3 \%$. Correlates of antenatal depression were identified, and these were low monthly income, unplanned pregnancy and previous history of abortion. Strengthening the counseling service as well as increasing access and availability of modern contraceptive methods may reduce the rates of unplanned pregnancy in Ethiopia and this, in turn, plays a significant role in alleviating a resultant depression. Further, the integration of mental health services with the existing maternal health care was warranted to reduce depression during pregnancy in West Shoa zone health facilities of Ethiopia.

\section{Limitations of the study}

We used a cross-sectional study design and a temporal relationship cannot be inferred using such a design. Usually, pregnant mothers start their antenatal follow-up at 
1216 weeks of gestation in Ethiopia. As a result, it was so difficult to recruit pregnant mothers in their 1st trimester of pregnancy. Hence, we recruited pregnant mothers in the 2nd and 3rd trimesters. However, epidemiologic evidence suggests the intergenerational transmission of depression begins as early as the initiation of conception. As a result, the inclusion of pregnant mothers in 2nd and 3rd trimesters may underestimate the prevalence of depression in the current study. However, we adjusted for the previous history of depression to check its association with the current depression. There was also the chance of recall bias since we have assessed depression once at 2nd or 3rd trimesters. Further, we used the average monthly income to investigate the individual income level. This could underestimate the wages assessment.

\section{Abbreviations}

EDPS: Edinburgh Postnatal Depression Scale; PHQ: Patient Health Questionnaire; PSS: Perceived stress scale; WHO: World Health Organization.

\section{Acknowledgements}

The authors express their deep appreciation to the college of medicine and health science of ethics committee of the Ambo University, as well as the West Shoa zone health bureau ethical committee for allowing this study to be conducted in the selected woredas. The authors would also like to acknowledge all the data collectors and supervisors as well as the study participants for their participation.

\section{Authors' contributions}

TT was involved in the conception, design, analysis, data interpretation and report writing. KT was has involved in the design, analysis and report writing. BD was involved in the statistical analysis, write-up and final editing for English language. All authors read and approved the final manuscript.

\section{Funding}

This study was funded by the Ambo University, Research and community service core process. The funder had no role in study design, data collection, analysis and decision to publish.

\section{Availability of data and materials}

The dataset pertaining to this study will be shared upon reasonable request.

\section{Ethics approval and consent to participate}

Before data collection, ethical clearance letter was obtained from the ethical clearance committee of Ambo University, college of medicine and health sciences. Formal letter of permission was obtained from the Woreda administration to the selected kebeles. Finally, oral and written informed consent was requested from the study participant after clearly explaining the objectives of the study. Also, written informed consent was obtained from a parent or guardian for participants under 16 years of age. The participants were also informed that they may withdraw themselves at any stage of the data collection period.

\section{Consent for publication \\ Not applicable.}

\section{Competing interest}

The authors declare that they have no competing interests.

\section{Author details}

${ }^{1}$ Department of Psychiatry Nursing, College of Medicine and Health Science, Ambo University, Ambo, Ethiopia. ${ }^{2}$ Department of Public Health, College of Medicine and Health Science, Ambo University, Ambo, Ethiopia. ${ }^{3}$ Faculty of Health Sciences, College of Medicine and Health Sciences, Hawassa
University, Hawassa, Ethiopia. ${ }^{4}$ School of Public Health, Curtin University, Perth, Australia.

Received: 14 December 2019 Accepted: 28 March 2020

Published online: 06 April 2020

\section{References}

1. American Psychiatric Association. Diagnostic and statistical manual of mental disorders: DSM-IV-TR. Washington: American Psychiatric Association; 2000.

2. World Health Organization (WHO). Depression: A Global Public Health Concern. https://www.who.int/mental_health/management/depression/ who_paper_depression_wfmh_2012.pdf.

3. World Health Organization, Depression and other common mental disorders, Global Health Estimates, 2017, https://www.who.int/mental_health/ management/depression/who_paper_depression_wfmh_2012.pdf.

4. Bassat Orellana Q, et al. Global, regional, and national age-sex-specific mortality and life expectancy, 19502017: a systematic analysis for the Global Burden of Disease Study 2017. Lancet. 2018;392(10159):1684-735.

5. Melville JL, Gavin A, Guo Y, Fan MY, Katon WJ. Depressive disorders during pregnancy: prevalence and risk factors in a large urban sample. Obstet Gynecol. 2013;116(5):1064-70.

6. Gelaye B, Rondon M, Araya R, Williams MA. Epidemiology of maternal depression, risk factors, and child outcomes in low-income and middleincome countries. Lancet Psychiatry. 2016;3(10):973-82.

7. World Health Organization 2008, The Global Burden of Disease 2004 update. https://www.who.int/healthinfo/global_burden_disease/2004_ report_update/en/.

8. WHO-UNFPA. Maternal mental health and child health and development in low and middle income countries. Geneva: Department of Mental Health and Substance Abuse; 2008.

9. Glasser S, Tanous M, Shihab S, Goldman N, Ziv A, Kaplan G. Perinatal depressive symptoms among Arab women in northern Israel. Matern Child Health J. 2012;16(6):1197-205.

10. Osborne LM, Monk C. Perinatal depression - the fourth inflammatory morbidity of pregnancy?: Theory and literature review. Psychoneuroendocrinology. 2013;38(10):1929-52.

11. Fatoye FO, Adeyemi AB, Oladimeji B. Emotional distress and its correlates among Nigerian women in late pregnancy. J Obstet Gynecol. 2004;24:504-9.

12. Shaunak A, Pradeep RJ, Nimisha NS. Risk factors predispose to depression during pregnancy. Ind Psychiatry J. 2013;22(1):37-40.

13. Grigoriadis S, VanderPorten E, Mamisashvili L, Tomlinson G, Dennis C, et al. The impact of maternal depression during pregnancy on perinatal outcomes: a systematic review and meta-analysis. J Clin Psychiatry. 2013;74(4):321-41.

14. Bindt C, Appiah-Poku J, TeBonle M, Schoppen S, Feldt T, Barkmann C, et al. Antepartum depression and anxiety associated with disability in African women: cross-sectional results from the CDS study in Ghana and cote d'Ivoire. PLoS ONE. 2012;7(10):48396.

15. Hashima E, Zarina N, Yvonne F, et al. Prevalence and associated factors of depressive and anxiety symptoms during pregnancy: a population based study in rural Bangladesh. BMC Women's Health. 2011;11:22.

16. Manikkam L, Burns JK. Antenatal depression and its risk factors: an urban prevalence study in KwaZulu-Natal. S Afr Med J. 2012;102(12):940-4. https://doi.org/10.7196/SAMJ.6009.

17. Rwakarema M, Premji S, Nyanza EC, Riziki P, Palacios-Derflingher L. Antenatal depression is associated with pregnancy-related anxiety, partner relations, and wealth in women in Northern Tanzania: a crosssectional study. BMC Women's Health. 2015;15:68.

18. Pirkola S, Isometsä E, Aro H, et al. Childhood adversities as risk factors for adult mental disorders. Soc Psychiat Epidemiol. 2005;40:769-77. https:// doi.org/10.1007/s00127-005-0950-x.

19. England MJ, Sim IJ, editors. Depression in parents, parenting, and children: Opportunities to improve identification, treatment, and prevention. Washington, DC: National Academies Press; 2009.

20. Garber J, Cole D. Intergenerational transmission of depression: a launch and grow model of change across adolescence. Dev Psychopathol. 2010;22(4):819-30. 
21. Verbeek T, Bockting CLH, Beijers C, Meijer JL, van Pampus MG, Burger H. Low socioeconomic status increases effects of negative life events on antenatal anxiety and depression. Women Birth. 2019;32(1):e138-43.

22. Sahile MA, Segni MT, Awoke T, Bekele D. Prevalence and predictors of antenatal depressive symptoms among women attending Adama Hospital Antenatal Clinic, Adama, Ethiopia. Int J Nurs Midwifery. 2017;9(5):58-64.

23. Bisetegn TA, Mihretie G, Muche T. Prevalence and predictors of depression among pregnant women in Debretabor town, northwest Ethiopia. PLOS ONE. 2016;11(9):e0161108.

24. Woldetensay YK, Belachew T, Tesfaye M, Spielman K, Biesalski HK, et al. Validation of the Patient Health Questionnaire (PHQ-9) as a screening tool for depression in pregnant women: Afaan Oromo version. PLOS ONE. 2018;13(2):e0191782.

25. Huizink AC, de Robles Medina PG, Mulder EJ, Visser GH, Buitelaar JK. Stress during pregnancy is associated with developmental outcome in infancy. J Child Psychol Psychiatry. 2003;44(6):810-8.

26. Cohen S, Kamarck T, Mermelstein R. Perceived stress scale. Measuring stress: a guide for health and social scientists. 1994. pp. 235-83. https:// www.mindgarden.com/132-perceived-stress-scale.

27. Ethiopian Demographic and Health Survey of 2016, https://dhsprogram .com/pubs/pdf/FR328/FR328.pdf.

28. Kaaya SF, Mbwambo JK, Kilonzo GP, et al. Socio-economic and partner relationship factors associated with antenatal depressive morbidity among pregnant women, Tanzanian. J Health Res. 2010;12:23-35.

29. Tefera, et al. Perinatal depression and associated factors among reproductive aged group women at Goba and Robe Town of Bale Zone, Oromia Region, South East Ethiopia. Maternal Health Neonatol Perinatol. 2015;1:12

30. Shah SM, Bowen A, Afridi I, Nowshad G, Muhajarine N. Prevalence of antenatal depression: comparison between Pakistani and Canadian women. J Pak Med Assoc. 2011;61:242-6.

31. Imran N, Haider II. Screening of antenatal depression in Pakistan: risk factors and effects on obstetric and neonatal outcomes. Asia-Pacific Psychiatry. 2010;2:26-32.

32. Afri SAM, Ali M, Ali R, ShaikhS Abid M, et al. Prevalence of depression among pregnant women attending antenatal clinics in Pakistan. Acta Psychopathol. 2017;3(5):54.

33. Hartley M, Tomlinson M, Greco E, et al. Depressed mood in pregnancy: prevalence and correlates in two Cape Town peri-urban settlements. Reprod Health. 2011;8:9. https://doi.org/10.1186/1742-4755-8-9.

34. KwaZulu-Natal Rochat TJ, Tomlinson M, Bärnighausen T, Newell ML, Stein A. The prevalence and clinical presentation of antenatal depression in rural South Africa. J Affect Disord. 2011;135:362-73. https://doi. org/10.1016/j.jad.2011.08.011

35. JUDITH OLECHA OSOK. depression and psychosocial risk factors associated with pregnant adolescents. H56/68337/2013.

36. Biratu A, Haile D. Prevalence of antenatal depression and associated factors among pregnant women in Addis Ababa, Ethiopia: a crosssectional study. Reprod Health. 2015;12:99. https://doi.org/10.1186/s1297 8-015-0092-x

37. Duko B, Ayano G, Bedaso A. Depression among pregnant women and associated factors in Hawassa city, Ethiopia: an institution-based crosssectional study. Reprod Health. 2019;16(1):25. https://doi.org/10.1186/ s12978-019-0685-X
38. Ogbo FA, Eastwood J, Hendry A, et al. Determinants of antenatal depression and postnatal depression in Australia. BMC Psychiatry. 2018;18:49. https://doi.org/10.1186/s12888-018-1598-x

39. Okechukwu T, Ike Oluwapo A. Prevalence of antenatal depression and associated risk factors among pregnant women attending antenatal clinics in Abeokuta North Local Government Area, Nigeria. Depress Res Treat. 2016;16:15.

40. Mossie TB, Sibhatu AK, Dargie A, Ayele AD. Prevalence of antenatal depressive symptoms and associated factors among pregnant women in Maichew, North Ethiopia: an institution based study. Ethiop J Health Sci. 2017;27(1):59-66.

41. Wickrama KA, Kwon JA, Oshri A, Lee TK. Early socioeconomic adversity and young adult physical illness: the role of body mass index and depressive symptoms. J Adolesc Health. 2014;55(4):556-63. https://doi. org/10.1016/j.jadohealth.2014.04.006.

42. Hall JA, Barrett G, Copas A, Phiri T, Malata A, Stephenson J. Reassessing pregnancy intention and its relation to maternal, perinatal and neonatal outcomes in a low-income setting: a cohort study. PLoS ONE. 2018;13(10):e0205487. https://doi.org/10.1371/journal.pone.0205487.

43. Assefa N, Berhane Y, Worku A, Tsui A. The hazard of pregnancy loss and stillbirth among women in Kersa, East Ethiopia: a follow-up study. Sex Reprod Healthc. 2012;3(3):107-12. https://doi.org/10.1016/j. srhc.2012.06.002.

44. Bahk J, Yun S, Kim Y, et al. Impact of unintended pregnancy on maternal mental health: a causal analysis using follow-up data of the Panel Study on Korean Children (PSKC). BMC Pregnancy Childbirth. 2015;15:85.

45. Phipps MG, Nunes AP. Assessing pregnancy intention and associated risks in pregnant adolescents. Matern Child Health J. 2012;16(9):1820-7. https ://doi.org/10.1007/s10995-011-0928-0.

46. Faisal-Cury A, Menezes P, Araya R, Zugaib M. Common mental disorders during pregnancy: prevalence and associated factors among low-income women in Sao Paulo, Brazil: depression and anxiety during pregnancy. Arch Womens Ment Health. 2009;12(5):335-43. https://doi.org/10.1007/ s00737-009-0081-6.

47. Faisal-Cury A, Rossi Menezes P. Prevalence of anxiety and depression during pregnancy in a private setting sample. Arch Womens Ment Health. 2007;10(1):25-32

48. Reardon DC. The abortion and mental health controversy: a comprehensive literature review of common ground agreements, disagreements, actionable recommendations, and research opportunities. SAGE Open Med. 2018;6:2050312118807624. https://doi.org/10.1177/2050312118 807624.

49. Pedersen W. Abortion and depression: a population-based longitudinal study of young women. Scand J Public Health. 2008;36(4):424-8.

50. Fergusson DM, Horwood $L$, Boden JM. Abortion and mental health disorders: evidence from a 30-year longitudinal study. Br J Psychiatry. 2008:193:444-51.

\section{Publisher's Note}

Springer Nature remains neutral with regard to jurisdictional claims in published maps and institutional affiliations.

Ready to submit your research? Choose BMC and benefit from

- fast, convenient online submission

- thorough peer review by experienced researchers in your field

- rapid publication on acceptance

- support for research data, including large and complex data types

- gold Open Access which fosters wider collaboration and increased citations

- maximum visibility for your research: over 100M website views per year

At $\mathrm{BMC}$, research is always in progress.

Learn more biomedcentral.com/submissions 